\title{
Prevalência e fatores associados à infecção pelo vírus da diarréia viral bovina na região Sul do Rio Grande do Sul
}

\section{Prevalence and factors associated with bovine viral diarrhea virus infection in South of Rio Grande do Sul}

\author{
Caren Gularte Quincozes ${ }^{1}$; Geferson Fischer ${ }^{1 *}$; Silvia de Oliveira Hübner ${ }^{1}$; \\ Gilberto D'Avila Vargas ${ }^{1}$; Telmo Vidor ${ }^{1}$; Claudiomar Soares Brod ${ }^{2}$
}

\section{Resumo}

O presente estudo teve como objetivo estimar a prevalência e determinar os principais fatores associados à infecção pelo vírus da diarréia viral bovina (BVDV) no rebanho bovino dos municípios de Santa Vitória do Palmar e Chuí, na região sul do estado do Rio Grande do Sul. Amostras de soro foram submetidas à prova de soroneutralização e, em cada propriedade avaliada, aplicou-se um questionário epidemiológico para investigar fatores que poderiam estar associados à infecção. As amostras de soro foram coletadas em 85 propriedades, cujos animais apresentavam ou não sinais clínicos de infecção pelo BVDV. Das 1.734 amostras de soro analisadas, $1.150(66,32 \%)$ foram positivas com a detecção de bovinos sorologicamente positivos em 70 (82,35\%) propriedades. Dentre os fatores avaliados, exploração mista, criação extensiva, realização de ordenha mecânica, uso de inseminação artificial ou de inseminação artificial associada à monta natural, uso de piquete de parição e ausência de assistência veterinária, apresentaram significância estatística $(\mathrm{P}<0,05)$ associada à soropositividade. Os resultados obtidos demonstram a expressiva disseminação do BVDV no rebanho bovino dessa região do Rio Grande do Sul. Palavras-chave: Bovinos, problemas reprodutivos, epidemiologia

\begin{abstract}
This study was performed in order to estimate the prevalence of bovine viral diarrhea virus (BVDV), and to determine the main factors related to the prevalence of the infection in cattle of Santa Vitória do Palmar and Chuí counties, in Rio Grande do Sul State. Sera were submitted to the serum neutralization test and an epidemiological questionnaire was filled out in each herd to investigate variables that could be associated with this infection. The sera samples were collected in 85 farms, with or without clinical signs of BVDV infection. From 1.734 serum samples examined, $1.150(66.32 \%)$ in $70(82.35 \%)$ herds were positive. Variables that were identified as risk factors to seropositivity were mixed (dairy and beef) herds, extensive production, use of mechanical milking, use of artificial insemination or artificial insemination associated with natural service, use of the maternity unit at calving and absence of veterinarian assistance $(\mathrm{P}<0.05)$. The results demonstrate the expressive dissemination of the BVDV in cattle of this region in Rio Grande do Sul.
\end{abstract}

Key words: Bovine, reproductive disorders, epidemiology

1 Laboratório de Virologia e Imunologia, Faculdade de Veterinária, Universidade Federal de Pelotas - UFPel - Caixa Postal 354 96010-900 - Pelotas - RS. e-mail: geferson.fischer@gmail.com

2 Centro de Controle de Zoonoses, Faculdade de Veterinária, Universidade Federal de Pelotas - UFPel - Caixa Postal 354 - 96010 900 - Pelotas - RS.

* Autor para correspondência 


\section{Introdução}

O vírus da diarréia viral bovina (BVDV), pertencente à família Flaviviridae, gênero Pestivírus (FRANCKI et al., 1991), é um agente infeccioso de distribuição mundial, cuja disseminação na população bovina do país foi comprovada por meio de isolamentos e inquéritos sorológicos (VIDOR; 1974; PITUCO et al., 1997; DIAS, SAMARA, 2003; FLORES et al., 2005). A infecção pelo BVDV pode resultar em uma grande variabilidade de sinais clínicos, relacionados com doença reprodutiva, respiratória ou digestiva (VOGEL et al., 2001; DIAS; SAMARA, 2003). A sua capacidade de cruzar a barreira placentária durante a gestação pode causar infertilidade temporária, queda nas taxas de concepção, morte embrionária e abortamentos (VIRAKUL et al., 1988; HOUE; PEDERSEN; MEYLING, 1993), mumificação fetal e natimortalidade (McCLURKIN et al., 1984; BROWNLIE; CLARK; HAWARD, 1989). Animais infectados no início da gestação podem nascer persistentemente infectados (PI), e se constituem numa fonte constante de infecção para animais não imunes (HOUE, 1995). Além de serem os maiores disseminadores do BVDV nos rebanhos, os animais PI estão sujeitos a desenvolver uma síndrome usualmente fatal, denominada doença das mucosas (DM) (LIESS et al., 1974).

O BVDV pode ser transmitido pela saliva, secreções nasais, oculares, urina, fezes, sêmen, embrião, placenta, sangue e fômites (REVELL et al., 1988; VOGEL et al., 2001), e se caracteriza por induzir altas taxas de soropositividade nos rebanhos expostos. A prevalência de animais soropositivos para o BVDV situa-se entre $60 \%$ a 90\% (BROWNLIE, 1989).

As vacinas propiciam proteção para a forma aguda das enfermidades causadas pelo BVDV, porém, não permitem livrar os rebanhos do vírus (BROCK, 2003), principalmente devido à existência de uma grande diversidade de cepas antigenicamente diferentes (PATON, 1995). A ausência de homologia entre as cepas sugere que vacinas produzidas com cepas consideradas padrão, ou isoladas de outros países, possam não estar conferindo imunidade adequada (FLORES et al., 2000).

Programas de controle e erradicação da infecção pelo BVDV sem o uso de vacinas têm sido implementados em alguns países europeus e são baseados na identificação de rebanhos infectados, descarte dos animais PI e certificação de rebanhos livres (LINDBERG; ALENIUS, 1999). A identificação de animais PI pode ser realizada com o auxílio da sorologia, uma vez que esses animais geralmente não apresentam anticorpos, ao contrário dos demais, que produzem altos títulos de anticorpos em resposta a infecção pelo BVDV (HOUE, 1995).

O presente trabalho foi realizado visando conhecer a situação epidemiológica da infecção pelo BVDV nos rebanhos bovinos dos municípios de Santa Vitória do Palmar e Chuí, na região sul do Estado do Rio Grande do Sul, por meio da determinação da prevalência e de possíveis fatores de risco associados a essa infecção.

\section{Material e Métodos}

Seleção das propriedades e fatores associados à infecção pelo $B V D V$

Utilizando-se uma expectativa de prevalência geral de $70 \%$, com um erro absoluto de $10 \%$ e um nível de confiança de $95 \%$, estimou-se um número mínimo de 81 propriedades a serem sorteadas aleatoriamente nos municípios em estudo, para serem avaliadas. Através das fichas de cadastro de produtores rurais da Inspetoria Veterinária e Zootécnica do Município de Santa Vitória do Palmar, os 1205 produtores, divididos em cinco extratos de acordo com o número de animais da propriedade, foram organizados em ordem alfabética, procedendose então o sorteio aleatório proporcional. Nas propriedades sorteadas, a amostragem dos animais a serem coletados levou em consideração o número total de animais da propriedade, ficando em $10 \%$, com nível de confiança de $95 \%$. O número de 
animais de cada propriedade foi dividido pelo número amostral calculado, para que fosse determinado o pulo amostral de coleta.

Para o estudo dos fatores eventualmente associados à infecção pelo BVDV foram preenchidos questionários onde constavam os dados referentes às propriedades e aos animais analisados. Os seguintes fatores foram avaliados: tipo de exploração (corte, leite ou mista), tipo de criação (extensiva, intensiva ou semi-intensiva), tipo de ordenha (manual ou mecânica), uso de inseminação artificial, ocorrência de aborto, presença de ovinos, uso de piquete para parto/pós-parto, assistência veterinária, sexo e idade.

\section{Sorologia}

Foram analisadas 1.734 amostras de soro sangüíneo, pertencentes a animais de 85 propriedades localizadas nos municípios em estudo, provenientes de bovinos de corte ou leite, machos ou fêmeas, com diferentes faixas etárias, apresentando ou não sinais clínicos de infecção por BVDV. As propriedades não apresentavam histórico de prévia vacinação para o BVDV.

O sangue foi coletado por punção da veia jugular, com agulhas descartáveis e sistema de vácuo, em tubos esterilizados. O soro foi separado do sangue total por centrifugação a $250 \mathrm{x}$ g, durante $15 \mathrm{~min}$. Em seguida, as amostras foram inativadas à $56^{\circ} \mathrm{C}$ em banho-maria por 30 minutos e estocadas a $-20^{\circ}$ $\mathrm{C}$ até o momento de uso.

A detecção de anticorpos neutralizantes para o BVDV foi feita através da técnica de soroneutralização, utilizando-se placas com 96 cavidades, conforme previamente descrito (FELDENS, 2000). Resumidamente, cada soro testado foi diluído em base logarítmica 2 a partir de $1: 4$ até 1:32. A cepa viral padrão utilizada, contendo $100 \mathrm{DICC}_{50} / 25 \mu \mathrm{L}$ (doses infectantes para $50 \%$ dos cultivos celulares/cavidade), foi a Oregon C24V (BVDVc, ATCC), com título infeccioso de 104,50 $\mathrm{DICC}_{50} / \mathrm{mL}$, calculado segundo o método de Behrens
\& Karber (MAYR et al., 1982). Como sistema indicador foram utilizadas células Madin Darby bovine kidney (MDBK). Foram considerados como títulos de anticorpos neutralizantes as recíprocas das maiores diluições do soro capazes de inibir a replicação viral e a conseqüente produção de efeito citopático. Em cada teste realizado foi incluído, além do controle de células, uma retrotitulagem das 100 $\mathrm{DI}_{50} / 25 \mu \mathrm{L}$, como controle do título da suspensão viral utilizada no teste.

\section{Análise estatística}

Para avaliar os efeitos de diferentes grupos etários, prováveis fatores de risco e manejo na prevalência de animais infectados com o BVDV, os dados foram amostrados no programa Epi Info Versão 6.04 (DEAN, A.; DEAN, J.; COULOMBIER, 1994). Foi usado o $\chi^{2}$ de Mantel-Haenzsel para tendência linear e "razão de chances" (OR), no intervalo de confiança de $95 \%$.

\section{Resultados e Discussão}

No presente inquérito sorológico sobre a infecção pelo BVDV, 1.150 (66,32\%) das 1.734 amostras analisadas foram positivas, indicando que a infecção ocorre com alta freqüência nos rebanhos bovinos dos municípios de Santa Vitória do Palmar e Chuí. A distribuição dos títulos de anticorpos foi a seguinte: $584(33,68 \%)$ amostras apresentaram títulos menores que 4; 207 (11,94\%) título 4; $242(13,96 \%)$ título 8; $267(15,40 \%)$ título 16 e, $434(25,03 \%)$ amostras apresentaram título $\geq 32$. Em $70(82,35 \%)$ das 85 propriedades avaliadas foram encontrados animais reagentes. As taxas de positividade por propriedade variaram de $14,29 \%$ a $100 \%$.

As variáveis analisadas como prováveis fatores associados à infecção pelo BVDV nas propriedades podem ser observadas na Tabela 1. Levando em conta o tipo de exploração, das 85 propriedades estudadas, $16(18,82 \%)$ realizavam exploração mista (corte e leite) e apresentaram prevalência de $77,24 \%$ e 1,73 
e 2,98 vezes mais chance de apresentarem animais positivos pelo BVDV do que propriedades com exploração exclusiva de corte ou de leite, respectivamente; 57 propriedades $(67,06 \%)$ eram de rebanhos de corte, e apresentaram prevalência de $66,18 \%$ e 1,73 vezes mais chances de apresentarem animais positivos, quando comparadas aquelas com exploração leiteira; 12 (14,12\%) criavam rebanhos de leite, e apresentaram prevalência de 53,23\%. Quanto ao tipo de criação, a maioria dos rebanhos analisados eram criados de forma extensiva, e esses apresentaram 2,77 vezes mais chances de apresentarem sorologia positiva para o BVDV em relação a rebanhos com criação semi-confinada. É possível que a maior prevalência observada nas propriedades mistas e de criação extensiva deva-se a inexistência ou a realização de um número muito reduzido de medidas direcionadas para o controle de problemas sanitários.

Tabela 1. Prevalência e fatores associados à infecção pelo vírus da Diarréia Viral Bovina em rebanhos nos municípios de Santa Vitória do Palmar e Chuí.

\begin{tabular}{|c|c|c|c|c|c|}
\hline & Variáveis & $\begin{array}{l}\text { Total de } \\
\text { animais }\end{array}$ & $\begin{array}{c}\text { Total de } \\
\text { positivos }\end{array}$ & $\begin{array}{l}\text { Valor } \\
\text { de p }\end{array}$ & Odds ratio ( $\left.\mathrm{IC}^{1} 95 \%\right)$ \\
\hline \multirow{6}{*}{ Exploração } & Mista & 312 & $241(77,24 \%)$ & $<0,001$ & $1,73(1,28<\mathrm{OR}<2,35)$ \\
\hline & Corte & 1174 & $777(66,18 \%)$ & -- & -- \\
\hline & Mista & 312 & $241(77,24 \%)$ & $<0,001$ & $2,98(2,04<\mathrm{OR}<4,36)$ \\
\hline & Leite & 248 & $132(53,23 \%)$ & -- & -- \\
\hline & Corte & 1174 & $777(66,18 \%)$ & $<0,001$ & $1,73(1,29<\mathrm{OR}<2,30)$ \\
\hline & Leite & 248 & $132(53,23 \%)$ & -- & -- \\
\hline \multirow[t]{2}{*}{ Criação } & Extensivo & 1689 & $1131(66,96 \%)$ & $<0,005$ & $2,77(1,47<\mathrm{OR}<5,27)$ \\
\hline & Semi-confinado & 45 & $19(42,22 \%)$ & -- & -- \\
\hline \multirow[t]{2}{*}{ Ordenha } & Manual & 348 & $212(60,92 \%)$ & -- & -- \\
\hline & Mecânica & 223 & $175(78,48 \%)$ & $<0,001$ & $2,34(1,56<\mathrm{OR}<3,50)$ \\
\hline \multirow{3}{*}{$\begin{array}{l}\text { Inseminação } \\
\text { artificial }^{2}\end{array}$} & Somente touro & 910 & $587(64,51 \%)$ & $=0,03$ & $1,90(1,00<\mathrm{OR}<3,60)$ \\
\hline & Inseminação + touro & 308 & $205(66,56 \%)$ & $=0,02$ & $2,08(1,06<\mathrm{OR}<4,09)$ \\
\hline & Somente inseminação & 47 & $23(48,89 \%)$ & -- & -- \\
\hline \multirow{2}{*}{$\begin{array}{l}\text { Presença de } \\
\text { ovinos }\end{array}$} & Sim & 1005 & $704(70,05 \%)$ & $<0,005$ & $1,48(1,21<\mathrm{OR}<1,83)$ \\
\hline & Não & 729 & $446(61,18 \%)$ & -- & -- \\
\hline \multirow{2}{*}{$\begin{array}{l}\text { Piquete de } \\
\text { parição/pós } \\
\text { parto }\end{array}$} & Sim & 613 & $414(67,54 \%)$ & $<0,005$ & $1,49(1,17<\mathrm{OR}<1,90)$ \\
\hline & Não & 609 & $355(58,30 \%)$ & -- & -- \\
\hline \multirow{2}{*}{$\begin{array}{l}\text { Assistência } \\
\text { Veterinária }\end{array}$} & Sim & 710 & $386(54,37 \%)$ & -- & -- \\
\hline & Não & 774 & $558(72,09 \%)$ & $<0,005$ & $2,17(1,73<\mathrm{OR}<2,71)$ \\
\hline \multirow{2}{*}{ Sexo } & Macho & 169 & $121(71,60 \%)$ & $=0,126$ & $1,31(0,91<\mathrm{OR}<1,90)$ \\
\hline & Fêmea & 1565 & $1029(65,75 \%)$ & -- & - \\
\hline
\end{tabular}

1 - Intervalo de confiança

${ }^{2}$ - Somente vacas com mais de 12 meses

O tipo de ordenha utilizada nas propriedades foi uma variável associada à soropositividade para o BVDV. O uso de ordenha mecânica em sala de ordenha resultou em um risco 2,34 vezes maior de o rebanho apresentar a infecção, comparado ao uso de ordenha manual. Embora não existam relatos da utilização de ordenha mecânica como sendo fator de risco para a infecção por BVDV, esta variável pode ser considerada, já que está associada à aglomeração de animais e, desse modo pode aumentar a probabilidade de transmissão do vírus.

Não houve diferença significativa da prevalência em relação a sexo e idade, embora tenha sido detectada maior freqüência para machos $(71,60 \%)$ e para a faixa etária de 7 e 12 meses $(78,26 \%)$. O 
aborto também não representou fator associado à infecção pelo BVDV, uma vez que a soropositividade em fêmeas que abortaram (61,54\%) foi semelhante à de fêmeas que não abortaram $(66,20 \%)$. Provavelmente a ausência de significância estatística possa ser explicada pelo pequeno número de ocorrências de aborto observado (39/681; 5,73\%) dentro de um grupo grande de animais susceptíveis de fêmeas aptas a parir.

Propriedades que utilizavam como forma de reprodução somente touro, ou inseminação artificial (IA) e touro, tiveram estes fatores associados à infecção pelo BVDV. Tais achados estão de acordo com dados anteriormente descritos (FRAY; PATON; ALENIUS, 2000) e significam que, quando foi comparada cada uma das modalidades de reprodução frente a IA, o uso de touro representou chance 1,90 vezes maior de presença da infecção, enquanto que o uso de inseminação e touro representou chance 2,08 maior. Esses resultados podem ser justificados pelo uso de touros infectados para a realização de cobertura natural, uma vez que pode ocorrer a transmissão por meio do sêmen contaminado. As conseqüências da utilização da monta natural estarão dependentes da eliminação ou não do vírus no sêmen no momento da monta, e do número de fêmeas cobertas.

O contato de bovinos com ovinos mostrou ser um fator associado à ocorrência da BVD, pois propriedades que criam ovinos tiveram chance 1,48 vezes maior de apresentarem a infecção do que propriedades que não criam ovinos. Estes animais são susceptíveis à infecção pelo BVDV e por isso é possível que tenham um importante papel na epidemiologia das infecções em bovinos (CELEDÓN et al., 2001; PESCADOR et al., 2004). O verdadeiro papel dos ovinos na transmissão de infecção aos bovinos deve ser analisado em maior profundidade em futuros trabalhos.

A utilização de piquetes separados para fêmeas nas fases de parto e/ou pós-parto aumentou a chance de infecção com o BVDV em 1,49 vezes. O esperado era que a separação dos animais fosse um fator de proteção para a infecção, pois impediria a disseminação para o restante do rebanho.

No presente estudo, a ausência de assistência veterinária foi considerada como fator para infecção pelo BVDV. As propriedades que não tiveram assistência veterinária apresentaram chance 2,17 vezes de infecção pelo BVDV, comparadas às propriedades que tiveram assistência veterinária. A falta de assistência veterinária pode ter se refletido especialmente no diagnóstico e na ausência de implementação de programas de controle da BVD.

A pesquisa sorológica realizada no presente estudo determinou a prevalência atual da infecção pelo BVDV nos rebanhos bovinos da região de Santa Vitória do Palmar e Chuí. A alta taxa $(66,32 \%)$ encontrada demonstra a ampla disseminação do BVDV nos rebanhos analisados. Os dados observados aproximam-se aos obtidos por Canal et al. (1998) que constataram anticorpos em 56\% dos 430 soros testados para o BVDV no Estado do Rio Grande do Sul. No Brasil, RICHTZENHAIM (1997), analisando 2.448 amostras provenientes de 56 propriedades em diversos Estados, encontrou uma prevalência que variou de $65 \%$ a $84 \%$. É provável que os fatores aqui analisados, aliados à presença de animais PI estejam relacionados à alta prevalência registrada.

A alta taxa de prevalência é um alerta para a implementação de medidas visando a prevenção e controle desta virose. A prevenção de novas infecções pode ser realizada utilizando-se uma combinação entre a remoção gradual dos animais infectados e a eliminação dos animais PI, a realização de quarentena no ingresso de bovinos na propriedade e exames sorológicos anuais, buscando impedir a reintrodução de animais infectados no rebanho (METTENLEITER, 1996). Além disso, como foi detectado no presente estudo, deve ser salientada a importância da utilização de sêmen livre de BVDV.

Para a prevenção e o controle da BVD também pode se fazer uso de vacinas, que podem fornecer imunidade aos animais suscetíveis e reforçar a imunidade naqueles anteriormente infectados. Os 
resultados sorológicos obtidos demonstraram que os níveis de anticorpos existentes nos animais não são compatíveis com proteção (VOGEL et al., 2001) e por isso a imunidade do rebanho deveria ser reforçada pelo uso de vacinação. Considerando que os níveis de anticorpos foram muito heterogêneos, e que os anticorpos podem bloquear a ação da vacina, é muito importante pensar no tipo de vacina que deveria ser utilizada. Vacinas que apresentam antígenos expostos são prejudicadas pela presença de anticorpos, portanto, vacinas oleosas, em que o óleo recobre o antígeno, seriam as mais adequadas, já que os anticorpos pré-existentes não interfeririam com a resposta imunológica. Futuramente, quando estiver disponibilizado o uso de vacinas moleculares, as quais permitem a diferenciação entre animais vacinados e infectados, serão favorecidas as práticas mais indicadas para a erradicação do BVDV.

\section{Conclusão}

A prevalência de infecção pelo vírus da diarréia viral bovina (BVDV) nos municípios de Santa Vitória do Palmar e Chuí, na região sul do Estado do Rio Grande do Sul, é elevada.

Os principais fatores associados à positividade para o BVDV foram: tipo de exploração mista, criação extensiva, realização de ordenha mecânica, uso de inseminação artificial ou de inseminação artificial associada à monta natural, uso de piquete de parição e, ausência de assistência veterinária.

Os altos coeficientes de prevalência encontrados indicam a necessidade de implementação de medidas para controlar e prevenir as doenças relacionadas ao BVDV.

\section{Referências}

BROCK, K. V. The persistence of bovine viral diarrhea virus. Biologicals, London, v.31, n.2, p.133-135, 2003.

BROWNLIE, J.; CLARK, M. C.; HOWARD, C. J. Experimental infection of cattle in early pregnancy with a cytopathic strain of bovine virus diarrhoea virus. Research Veterinary Science, London, v.46, n.3, p.307-311, 1989.

CANAL, C. W.; STRASSER, M.; HERTIG, C.; MASUDA, A.; PETERHANS, E. Detection of antibodies to bovine viral diarrhoea virus (BVDV) and characterization of genomes of BVDV from Brazil. Veterinary Microbiology, Amsterdam, v.63, n.2-4, p.85-97, 1998.

CELEDÓN, M.; SANDOVAL, A.; DROGUETT, J.; CALFIO, R.; PIZARRO, J.; NAVARRO, C. Pesquisa de anticuerpos seroneutralizantes para pestivirus y herpesvirus en ovinos, caprinos y camélidos sudamericanos de Chile. Archivos de Medicina Veterinaria, Valdivia, v.33, n.2, p.165-172, 2001.

DEAN, A. G.; DEAN J. A.; COULOMBIER, D. Epi Info Version 6.0. A word processing, database, and statistics program for epidemiology on microcomputers. Atlanta : Centers for Disease Control and Prevention, 1994.

DIAS, F. C.; SAMARA, S. I. Detecção de anticorpos contra o vírus da diarréia viral bovina no soro sangüíneo, no leite individual e no leite de conjunto em tanque de expansão de rebanhos não vacinados. Brazilian Journal of Veterinary Research and Animal Science, São Paulo, v.40, n.3, p.161-168, 2003.

FELDENS, O. Avaliação do efeito paraimune de extratos vegetais (Nicotiana glauca e Chrysanthemum vulgaris) em bovinos vacinados contra o Herpesvírus bovino tipo 5 (HVB-5). 2000. 51p. Dissertação (Mestrado em Medicina Veterinária) - Universidade Federal de Pelotas, Pelotas.

FLORES, E. F.; WEIBLEN, R.; SCHERES, C. F. C.; GIL, L. H. V. G.; PILATI, C.; DRIEMEIER, D.; MOOJEN, V.; WENDELSTEIN, A. C. Identificação do vírus da Diarréia Viral Bovina tipo 2 (BVDV-2) no sul do Brasil. Pesquisa Veterinária Brasileira, Rio de Janeiro, v.20, n.2, p.85-89, 2000.

FLORES, E. F.; WEIBLEN, R.; VOGEL, F. S. F.; ROEHE, P. M.; ALFIERI, A. A.; PITUCO, E. M. A infecção pelo vírus da Diarréia Viral Bovina (BVDV) no Brasil - histórico, situação atual e perspectivas. Pesquisa Veterinária Brasileira, Rio de Janeiro, v.25, n.3, p.125-134, 2005.

FRANCKI, R. I. B.; FAUQUET, C. M.; KNUDSON, D. L.; BROWN, F. Classification and nomenclature of viruses. Archives of Virology, New York, p.228-229, 1991. suppl.2. 
FRAY, M. D.; PATON, D. J.; ALENIUS, S. The effects of bovine viral diarrhoea virus on cattle reproduction in relation to disease control. Animal Reproduction Science, Amsterdam, v.60-61, n.1-3, p.615-627, 2000.

HOUE, H.; PEDERSEN, K. M.; MEYLING, A. The effect of bovine virus diarrhoea virus infection on conception rate. Preventive Veterinary Medicine, Amsterdam, v.15, p.117123, 1993.

HOUE, H. Epidemiology of bovine viral diarrhea virus. The Veterinary Clinics of North America, Philadelphia, v.11, n.3, p.521-548, 1995.

LIESS, B.; FREY, H. R.; KITTSTEINER, H.; BAUMANN, F.; NEUMANN, N. Beobachtungen und Untersuchungen über die "Mucosal Disease" des Rindes. Deutsche Tierärztliche Woschenschrift, Hannover, v.81, p.477-500, 1974.

LINDBERG, A.; ALENIUS, S. Principles for eradication of bovine viral diarrhoea virus (BVDV) infections in cattle populations. Veterinary Microbiology, Amsterdam, v.64, p.197-222, 1999.

MAYR, A.; BACHMANN, P. A.; BIBRACK, B. M.; WITHMANN, G. Virologische Arbeitsmethoden: Band IV - Sicherheit bei virologischen arbeiten - Biometrische methoden. Stutgart: Gustav Fischer Verlag, 1982.

McCLURKIN, A. W.; LITTLEDIKE, E. T.; CUTLIP, R. C.; FRANK, G. H.; CORIA, M.. F.; BOLIN, S. R. Production of cattle imunotolerant to bovine viral diarrhea virus. Canadian Journal Comparative Medicine, Ottawa, v.48, p.156-161, 1984.

METTENLEITER, T. C. Conclusions from the symposium. Veterinary Microbiology, Amsterdam, v.53, p.207-211, 1996.
PATON, D.J. Pestivirus diversity. Journal of Comparative Pathology, Edinburgh, v.112, p. 215-236, 1995.

PESCADOR, C. A.; CORBELLINI, L. G.; DRIEMEIER, D.; GONÇALVES, R. K.; CRUZ, C. E. F. Neurological disorder associated with pestivirus infection in sheep in Rio Grande do Sul, Brazil. Ciência Rural, Santa Maria, v.34, p. 935938, 2004.

PITUCO, E. M.; DEL FAVA, C.; OKUDA, L. H.; STEFANO, E. de; BILINSKYJ, M. C. V.; SAMARA, S. I. Prevalência da infecção pelo vírus da diarréia bovina à vírus (BVD) em búfalos (Bubalus bubalis) no vale do Ribeira, SP, Brasil. Arquivos do Instituto Biológico, São Paulo, v.64, p.23-28, 1997.

REVELL, S. G.; CHASEY, D.; DREW, T. W.; EDWARDS, S. Some observations on the semen of bulls persistently infected with bovine viral diarrhoea virus. Veterinary Record, London, v.123, p.122-125, 1988.

RICHTZENHAIN, L. J. Em busca de respostas. Revista Criadores, São Paulo, n.808, p.40, 1997.

VIDOR, T. Isolamento e identificação do vírus da Doença das Mucosas no Rio Grande do Sul. Boletim do Instituto de Pesquisa Veterinária Desidério Finamor, p.51-58, 1974. Especial 2.

VIRAKUL, P.; FAHNING, M. L.; JOO, H. S.; ZEMJANIS, R. Fertility of cows challenged with a cytopathic strain of bovine virus diarrhea virus during an outbreak of spontaneous infection with a noncytopathic strain. Theriogenology, Stoneham, v.29, p.441-449, 1988.

VOGEL, F. S. F.; SCHERER, C. F. C.; FLORES, E. F.; WEIBLEN, R.; LIMA, M.; KUNRATH, C. F. Resposta sorológica e avaliação de proteção fetal em ovelhas prenhes vacinadas contra o vírus da diarréia viral bovina (BVDV). Ciência Rural, Santa Maria, v.31, p.831-838, 2001. 
